\title{
Standard and method independent units for heparin anticoagulant activities
}

Citation for published version (APA):

Hemker, H. C., \& Beguin, S. (1993). Standard and method independent units for heparin anticoagulant activities. Thrombosis and Haemostasis, 70(5), 724-728. https://doi.org/10.1055/s-0038-1649659

Document status and date:

Published: 01/01/1993

DOI:

10.1055/s-0038-1649659

Document Version:

Publisher's PDF, also known as Version of record

\section{Please check the document version of this publication:}

- A submitted manuscript is the version of the article upon submission and before peer-review. There can be important differences between the submitted version and the official published version of record.

People interested in the research are advised to contact the author for the final version of the publication, or visit the DOI to the publisher's website.

- The final author version and the galley proof are versions of the publication after peer review.

- The final published version features the final layout of the paper including the volume, issue and page numbers.

Link to publication

\footnotetext{
General rights rights.

- You may freely distribute the URL identifying the publication in the public portal. please follow below link for the End User Agreement:

www.umlib.nl/taverne-license

Take down policy

If you believe that this document breaches copyright please contact us at:

repository@maastrichtuniversity.nl

providing details and we will investigate your claim.
}

Copyright and moral rights for the publications made accessible in the public portal are retained by the authors and/or other copyright owners and it is a condition of accessing publications that users recognise and abide by the legal requirements associated with these

- Users may download and print one copy of any publication from the public portal for the purpose of private study or research.

- You may not further distribute the material or use it for any profit-making activity or commercial gain

If the publication is distributed under the terms of Article $25 \mathrm{fa}$ of the Dutch Copyright Act, indicated by the "Taverne" license above, 


\title{
EDITORIAL
}

\section{Standard and Method Independent Units for Heparin Anticoagulant Activities}

\author{
H. C. Hemker and S. Béguin \\ From the Department of Biochemistry, Cardiovascular Research Institute and University of Limburg, \\ Maastricht, The Netherlands
}

\section{Summary}

It is discussed why the current USP unit of heparin anticoagulant activity necessarily will render inaccurately the anticoagulant activities of low molecular weight heparins. It is shown that the outcome is bound to vary with the method used for comparison of the sample and the standard and with the nature of the standard used. As an alternative we define a unit of heparin in terms of anti-factor $\mathrm{Xa}$ - and antithrombin-activity that is independent of the heparin standard and of the assay method, but that is based upon a quantitative description of the catalytic effect of heparin on AT III mediated thrombin- and factor Xa breakdown. Expression of the results of existing anti-factor $\mathrm{Xa}$ - and antithrombin tests in terms of these units will allow to express heparin levels in plasma in terms of concentrations of active anticoagulant material. This approach makes it possible to separate heparin pharmacodynamics from heparin pharmacokinetics. Introduction of this unit does not require adaptation of current laboratory practice but changes the way in which the results obtained are expressed.

\section{Introduction}

In the early 1920's, Howell (1) defined a unit of heparin as that amount of heparin that causes such retardation of coagulation that a millilitre of cat blood will half-clot when left during one night in the refrigerator. The United States Pharmacopoeia (USP unit), that also figures in many national pharmacopoeias, is similarly defined as that amount of heparin that will cause $1 \mathrm{ml}$ of sheep plasma to half-clot when kept for $1 \mathrm{~h}$ at $37^{\circ} \mathrm{C}$ (see also 2 for a discussion). The International Unit (I. U.) is defined via the International Heparin Standard (I. H.S.) which itself is calibrated via all the major assay methods.

The direct determination of heparin concentrations in plasma from patients is impossible with the USP method. A large number of other tests is available for this purpose: thrombin time, activated partial thromboplastin time in a multitude of varieties

Abbreviations used: AT III: antithrombin III; USP: United States pharmacopoeia; IU: International unit; SIU: standard independent unit; UFH: unfractionated heparin; LMWH: low molecular weight heparin; HAM: high affinity material; ACLM: above critical chainlength material; BCLM: below critical chainlength material; APTT: activated partial thromboplastin time.

Correspondence to: Dr. H. C. Hemker, Dept. of Biochemistry, Cardiovascular Research Institute of Limburg, P. O. Box 616, 6200 MD Maastricht, The Netherlands
(APTT), and several tests based on the measurement of the decay of added thrombin or factor Xa. In order to express the results of these tests in terms of USP units, they need to be calibrated with a standard preparation, the potency of which has been determined in terms of USP procedure. An important problem in the determination of the heparin concentration by comparison to a standard remains, however, that the outcome will be dependent upon the method used for comparison (see below).

The anticoagulant effect used for the definition of the USP unit is far from being specific; any anticoagulant activity can be expressed in these units. Therefore the USP unit can be used in a meaningful way only as long as fairly similar preparations of heparin are compared. It appears to be a poor tool even to compare low molecular weight heparins to the unfractionated heparin standard $(3,4)$. Indeed its replacement is being considered $(5,6)$. Replacement by what, however? In this paper we propose a unit of heparin activity that is not dependent upon the use of a special method and that also is not primarily defined as the activity of a given standard preparation even though in practice standard preparations will remain a necessary means to compare the results in different laboratories.

\section{Biochemical Backgrounds: Heparin}

Heparins act on blood coagulation by binding to AT III and enhancing its inhibitory action on thrombin, factor Xa and other blood coagulation enzymes $(7-10)$. Active heparins contain a specific pentasaccharide sequence with which they bind to AT III (see 11 for a review). Only about $30-40 \%$ (weight) of UFH contains this sequence. This fraction we call High Affinity Material (HAM). Within HAM we distinguish two classes (Fig. 1): molecules longer than the critical chainlength of 17 monosaccharide units (Above Critical chain Length Material: ACLM, with a $\mathrm{Mw}>5,400$ ) and molecules below that chainlength (BCLM). ACLM catalyses both factor Xa and thrombin inactivation but BCLM catalyses only factor Xa-inactivation. As discussed in detail in ref. 12 (pp 23-26 and references therein), the cutoff point between ACLM and BCLM heparins can indeed be localised with fair precision around $5,400 \mathrm{MW}$ or 17 monosaccharide units. Our own data also support this conclusion $(13,14)$.

Different types of heparin may differ as to the HAM content as well as to the partition of the HAM fraction between ACLM and BCLM. In a series of 4 commercially available LMWH preparations the ACLM contents ranged from 10 to $30 \%$ and the BCLM contents from 1 to $12 \%$. The HAM content of LMWHs decreases proportionally with the mean molecular weight (14). This seems a logical consequence from the fact that LMWHs are obtained from UFH by chemical or enzymatical splitting of the molecules in a random fashion. A HAM molecule of around 9,000 MW will consist of some 30 monosaccharide units. If such a molecule is 
Table 1 Comparison of the activities of different heparins

\begin{tabular}{|c|c|c|c|c|c|c|}
\hline & \multirow{2}{*}{$\begin{array}{l}\text { HAM } \\
\mu \mathrm{g} / \mathrm{ml}\end{array}$} & \multirow{2}{*}{$\begin{array}{l}\text { HAM } \\
\mu \mathrm{M}\end{array}$} & \multicolumn{2}{|c|}{$\begin{array}{l}\text { International } \\
\text { Units }\end{array}$} & \multicolumn{2}{|c|}{ S. I. Units } \\
\hline & & & $\mathrm{aXa}$ & aIIa & $\mathrm{aXa}$ & aIIa \\
\hline \multicolumn{7}{|c|}{ A: IC50 of the surface under the thrombin generation curve (intrinsic) } \\
\hline UFH & 0.077 & 0.0074 & 0.025 & 0.025 & 0.373 & 1.198 \\
\hline LMWH 1 & 0.153 & 0.030 & 0.065 & 0.022 & 0.357 & 1.164 \\
\hline LMWH 2 & 0.189 & 0.042 & 0.090 & 0.027 & 0.434 & 1.047 \\
\hline PENTA & 0.800 & 0.480 & 0.520 & - & 0.495 & - \\
\hline \multicolumn{7}{|c|}{ B: Dose doubling the APTT } \\
\hline UFH & 0.62 & 0.059 & 0.192 & 0.192 & 1.97 & 6.36 \\
\hline LMWH 1 & 2.1 & 0.420 & 0.9 & 0.3 & 3.29 & 10.72 \\
\hline LMWH 2 & 2.1 & 0.470 & 1.0 & 0.3 & 3.20 & 7.72 \\
\hline PENTA & 50 & 29.40 & 32.5 & - & 165 & - \\
\hline
\end{tabular}

Thrombin generation curves were determined as in ref. 13. The APTT was carried out manually by mixing $0.1 \mathrm{ml}$ plasma sample, $0.1 \mathrm{ml}$ Actin FS (Baxter Diagnostics), after 2 min mixing at $37^{\circ} \mathrm{C}, 0.1 \mathrm{ml} \mathrm{CaCl}(25 \mathrm{mM})$ was added and the clotting time read by tilting. The dose was sought that in 9 out of 10 experiments prolonged the blank of $35 \mathrm{~s}$ to between 68 and $72 \mathrm{~s}$. Molar concentrations of HAM were obtained directly via AT III fluorescence titration.

split in two random parts, than there is a 5 in 30 chance that the pentasaccharide sequence will be split that is responsible for AT III binding and two LAM molecules will result.

\section{Biochemical Backgrounds: Kinetics of Clotting Factor Decay}

The inactivation of thrombin, factor $\mathrm{Xa}$ and other activated clotting enzymes by AT III in plasma is a bimolecular reaction $\left(E+A \stackrel{k}{\rightarrow} I^{*}\right)$ that according to standard chemical kinetics has a reaction velocity of $v_{t}=k \cdot A_{t} \cdot E_{t}$. The concentration of AT III in plasma is about $2.5 \mu \mathrm{M}$. In every well designed decay experiment care is taken to keep the initial enzyme concentration below a certain proportion (e.g. 30 times less) of the AT III concentration. Therefore $A_{t}$ can be considered constant and the enzyme decay can be described by pseudo-first order kinetics. The decay velocity of the enzyme is therefore expressed by $v_{t}=k \cdot A_{0} \cdot E_{t}$, or $v$ $=k_{\mathrm{dec}} \cdot E_{t}$, where $k_{\mathrm{dec}}=k \cdot A_{0}$. In this situation the time-course of $E$ is given by $E_{t}=E_{0} \cdot \mathrm{e}^{-k_{\text {dec }} \cdot t} ;$ i. e. the enzyme decays semilogarithmically as e.g. a radioactive element. The decay constant is inversely proportional to the half-life time of the enzyme: $k_{\mathrm{dec}}=0.693 / t_{1 / 2} * *$. The dimension of $k_{\mathrm{dec}}$ therefore is inverse time, usually it is expressed in $\mathrm{min}^{-1}$. Heparin catalyses the above reaction. The mechanism of catalysis may be complex (15), its effect is simple: it decreases the half-life time and increases the decay constant $k_{\mathrm{dec}}$. In plasma, at heparin concentrations that may be encountered in actual prophylactic and therapeutic practice, the increase of the decay constant is proportional to the AT III concentration and to the concentration of heparin: $k_{\mathrm{dec}}=k \cdot A \cdot H$. This proportionality, that was found for all the different heparins that we tested $(13,14,16-18)$, we will use as a basis for the definition of a heparin unit. It is important to notice that in this formula $H$ stands for the concentration of active heparin. For the decay of factor Xa only

* In the reaction equation $E=$ enzyme (thrombin, factor Xa etc.), $A=$ AT III, $I=$ inactive product. In the kinetic equations the letters stand for the concentrations of these reactants. The subscripts denote the time, $E_{0}=$ enzyme concentration at zero time etc.

** Because at the half-life time half of the original material is left, and the natural logarithm of $1 / 2$ equals -0.693 .
HAM molecules count, for the decay of thrombin only the ACLM fraction.

\section{The Confusion Inherent to the Old Units}

Inhibition of blood clotting, as used in the determination of the USP unit or the APTT, can be obtained both by ACLM and by BCLM, but the activity per unit weight of ACLM is much higher than that of $\operatorname{BCLM}(13,14)$. In Table 1 it is seen that concentrations of different heparins with comparable biological activity on thrombin generation or the APT differ considerably in weight volume or molar terms and in anti- $X_{a}$ activity. Consequently $1 \mu \mathrm{g}$ of BCLM contains less USP units of heparin activity than $1 \mu \mathrm{g}$ of ACLM. In a test based on the anti-factor Xa activity of heparin, BCLM will be about equally active as ACLM is, because the specific anti-Xa activities of ACLM and BCLM, when expressed on a molar basis, are roughly equal (Table 2, see also below). In a test based on the antithrombin action of heparin, however, BCLM will not count at all. The relative importance of ACLM and BCLM for the test outcome is therefore completely dependent upon the test used.

Obviously only a standard with an identical ratio of ACLM :BCLM as the sample to be tested will not be influenced by the type of test used. This is the rationale behind the usefulness of the a LMWH standard (4). This standard is a mixture of ACLM and BCLM, the composition of which approaches the composition of other LMWHs better than the UFH standard does. But the units of a LMWH standard, nor of any other LMWH can be compared to units of UFH, in which hardly any BCLM is present.

A second complication is that the UFH standard, like all other UFHs but unlike LMWHs, has a low anti-factor Xa activity in the absence of $\mathrm{Ca}^{2+}$, i. e. in all current anti-Xa tests. Any LMWH in these tests is measured against a "handicapped" standard and hence is overestimated (19).

The following may serve as an illustration. We took 0.01 USP unit of standard heparin and determined the amount of a LMWH that in a commercial, amidolytic anti-factor Xa test showed the same activity, so that by definition it contained also 0.01 USP unit of anti-factor Xa activity. This, in fact is the way in which the manufacturers arrive at the amount of activity declared on the label. For technical reasons current anti-factor $\mathrm{Xa}$ tests are carried out in the absence of $\mathrm{Ca}^{2+}$ ions. We estimated the anti-factor $\mathrm{Xa}$ activity of the standard heparin preparation and of the "equipotent" LMWH solution in the presence of a physiological concentration of $\mathrm{Ca}^{2+}$ ions and found the UFH preparation to be 1.37 times as potent as the LMWH. In the body heparin acts in the presence of $\mathrm{Ca}^{2+}$ ions, so the label of the LMWH must be judged to overestimate the contents by 1.86 times (see also 19).

So the label on the LMWH bottle overestimates the potency of its contents nearly two times. Similar results were obtained with other LMWHs, including the international standard for LMWH.

The confusion stems from two sources. In the first place the test conditions may differ considerably from the conditions in the body. In the second place we try to assign a unique potency to a drug that, at the simplest, is a mixture of two distinct active substances: ACLM and BCLM, the proportion of which is not the same in the standard and in the preparation to be tested.

\section{A Proposal for Standard- and Method Independent Units}

In the presence of HAM the decay constant of factor $\mathrm{Xa}$ increases proportionally to the heparin-concentration and to the concentration of AT III in the plasma. This property we can use to define a standard- and method independent unit (SIU) of HAM activity $(16,17)$

Definition. One standard independent unit of anti-factor $\mathrm{Xa}$ activity (SIU-Xa), of heparin is that amount of heparin that, in 


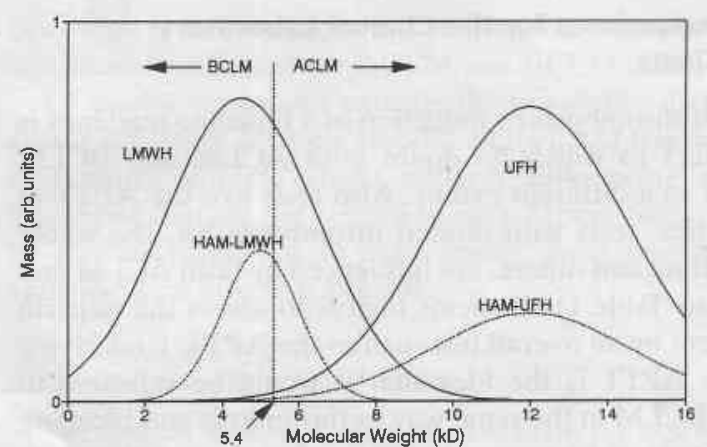

Fig. 1 Schematic representation of the molecular weight distribution in unfractionated and in low molecular weight heparin (see text)

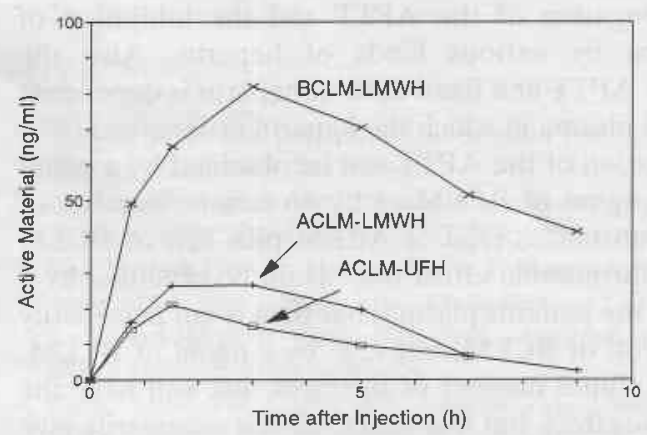

Fig. 2 The course of ACLM and BCLM leveis after injection of UFH and LMWH. At zero time a subcutaneous injection was given of UFH (22 $\mathrm{mg}$, containing $7.3 \mathrm{mg}$ of ACLM and no detectable BCLM) and of LMWH (30 mg, containing $3.8 \mathrm{mg}$ ACLM and $3.2 \mathrm{mg}$ BCLM). No significant levels of BCLM were found when UFH was injected. (From ref. 16, to which we refer for details on materials and methods)

normal plasma, increases the decay constant of factor Xa by $1 \mathrm{~min}^{-1}$ per $\mu M$ of plasmatic AT III.

The heparin activity thus measured is the activity of all HAM, i. e. both BCLM and ACLM. Varying amounts of ACLM within the same total amount of HAM will not be distinguished by the anti-Xa activity. We therefore also need to define a unit of antithrombin activity. The decay velocity of thrombin in plasma increases proportionally with the ACLM concentration and with the AT III concentration (17). We can therefore define a standard- and method independent unit of anti-thrombin activity completely analogous to the anti-factor Xa unit.

Definition. One standard independent unit of anti-thrombin activity of heparin (SIU-IIa), is that amount of heparin that, in normal plasma, increases the decay constant of thrombin by $1 \mathrm{~min}^{-1}$ per $\mu \mathrm{M}$ of plasmatic AT III.
The units thus defined are not dependent upon a standard or upon a specific methodology. This does not mean that in practice one or more heparin standards would not be useful or even necessary. The use, in the definition, of the words "in normal plasma" implies that the reaction conditions should be as near as possible to physiological $\mathrm{Ca}^{2+}$ concentration, temperature, quality of enzyme, presence of other proteins etc. Reproducible results in different laboratories can only be obtained if the methods are rather strictly defined. If the method is not completely defined then the use of a standard calibrated in the new units can minimise errors due to experimental variations. In principle the deviations from physiological conditions do not count then any more, and any anti-thrombin or anti-factor Xa method that is now in use can be applied to determine heparin contents in terms of the new units, when thus calibrated against well defined standards of anti-factor $\mathrm{Xa}$ - and anti-thrombin activity. The only caveat is that the standard and the heparin in question should react in the same way to changes in the reaction conditions. This is not the case e.g. when LMWHs are compared to a UFH standard in mixtures without $\mathrm{Ca}^{2+}$ ions $(19$, see also above). From Table 1 it is seen that heparin concentrations that have similar effects on thrombin generation have comparable activities when expressed in S.I. Units.

\section{Specific Activities of Heparins, their Use in Heparin Pharmacology}

We can express the specific activity of a heparin in terms of the SI units. To do this, we determine how much $1 \mu \mathrm{g}$ of the heparin under investigation will increase the decay constants of factor Xa and of thrombin in a normal plasma with a known AT III content. If the addition of $1 \mu \mathrm{g}$ of the heparin to $1 \mathrm{ml}$ of plasma increases the decay constant from $0.490 \mathrm{~min}^{-1}$ (the normal value without heparin) to $4.740 \mathrm{~min}^{-1}$ per $\mu \mathrm{M}$ of $\mathrm{AT} \mathrm{III,} \mathrm{than} \mathrm{the} \mathrm{specific}$ activity of that heparins is 4.250 SIU-Xa per $\mu \mathrm{g}$ of crude material. In the crude material only the HAM is responsible for this activity, it therefore is logical to express this activity per $\mu \mathrm{g}$ or per nMole of HAM (Table 2).

In a completely analogous way we can determine the specific anti-thrombin activity of a heparin. Again from the specific activity of the crude material one can calculate the specific activity per $\mu G$ or nMole of active heparin species, i.e. of the ACLM fraction (Table 2).

It should be stressed that these specific activities are inherent properties of a heparin, defined completely by the catalytic potencies of the preparation only and independent of the method with which they are obtained.

Once the specific anti-factor Xa activity of the HAM material of a given heparin is known, we can use the SIU-Xa level of a plasma sample to determine its concentration of HAM by simply dividing that level by the specific anti-factor Xa activity of the HAM that is administered (16). If our conjecture on the identical

Table 2 Specific activities of a LMW heparin and its subfractions

\begin{tabular}{|c|c|c|c|c|c|c|}
\hline \multirow[b]{2}{*}{ Heparin } & \multirow[b]{2}{*}{$\begin{array}{l}\text { MW } \\
\text { (dalton) }\end{array}$} & \multicolumn{3}{|c|}{ Specific anti-IIa act. per: } & \multicolumn{2}{|c|}{ Spec. anti-Xa act. per: } \\
\hline & & $\begin{array}{l}\mu g \\
\text { crude }\end{array}$ & $\begin{array}{l}\text { nMole } \\
\text { HAM }\end{array}$ & $\begin{array}{l}\text { nMole } \\
\text { ACLM }\end{array}$ & $\begin{array}{l}\mu \mathrm{g} \\
\text { crude }\end{array}$ & $\begin{array}{l}\text { nMole } \\
\text { HAM }\end{array}$ \\
\hline Fraxiparin & 5,100 & 2.36 & 56 & $>106$ & 0.72 & 17.1 \\
\hline HAM, total & 5,400 & 5.96 & 42 & 79 & 2.57 & 18.0 \\
\hline HAM, medium MW & 7,740 & 16.88 & 136 & 140 & 1.77 & 14.3 \\
\hline HAM, low MW & 4,620 & 0.62 & 3 & 7 & 3.66 & 17.8 \\
\hline HAM, ultralow MW & 3,400 & 0.00 & 0 & 0 & 3.46 & 21.0 \\
\hline
\end{tabular}

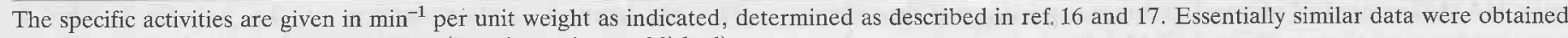
with Enoxaparin and Logiparin fractions (Béguin et al. unpublished). 
specific activity of all HAM would prove to be true, as suggested by the data of Table 2, than the SIU-Xa value would indicate the number of active HAM molecules in the sample independent of the type of heparin injected. Also if it is not true, then the SIU-Xa value still indicates the level of HAM in terms of a mean of the molar activity. Analogously to the HAM level, the ACLM level of a plasma sample can be obtained by dividing its SIU-IIa value by the specific anti-thrombin activity of the ACLM fraction of the material injected.

Thus the definition of SI units and the determination of specific heparin activities enables us to assess separately the levels of ACLM and BCLM (BCLM = HAM - ACLM) in the circulation. This means that we can discuss heparin pharmacokinetics in terms of concentrations of active molecules. Pharmacokinetics can in this way be separated from pharmacodynamics. In order to get an impression of the heparin concentration of a sample it is no longer necessary to compare two pharmacodynamic effects such as the prolongation of the APTT and the thrombotic or bleeding tendency, Fig. 2 gives an example of this approach (from ref. 16).

The TFPI content of the patients sample will as such not significantly influence the half-life time of thrombin or factor $\mathrm{Xa}$ in plasma. TFPI has no influence on thrombin. The absolute concentrations of TFPI are maximally $5 \mathrm{nM}(20)$, which is small compared to the amount of factor Xa used in decay experiments (around $100 \mathrm{nM}$ ). Also the action of TFPI is practically immediate, so that it will not play a role in the time-domain of a decay experiment (min). Any other action of TFPI is dependent upon the presence of tissue thromboplastin, which is absent in antifactor Xa assays. TFPI therefore will not significantly influence the SIU-aXa determination and not at all the SIU-aIIa determination.

\section{Practical Consequences for the Clinical Laboratory: Anti-Thrombin and Anti-Factor $\mathrm{Xa}$ Tests}

Any well-designed anti-thrombin test is dependent upon thrombin breakdown-velocity only. Likewise good anti-factor Xa activity tests will only measure factor $\mathrm{Xa}$ breakdown velocity. Therefore these tests already measure $k_{\mathrm{dec}}$, only the results are not expressed in an appropriate way. If standards calibrated in SI units would be available, a conversion coefficient can be found for each method and no important changes in everyday laboratory practice would be required for the adoption of the SI unit.

The results of monospecific tests can than be expressed directly in standard independent units by multiplication with the conversion coefficient. This coefficient will be different for different tests. In any given case it can be determined by calibration of the test against a $k_{\mathrm{dec}}\left(t_{1 / 2}\right)$ determination or against a heparin preparation of which the potency is known in terms of SI units. This brings back the heparin standard, but it is no longer the standard that defines the unit. The standard is now a tool for calibration that can be abandoned by those who prefer to measure $k_{\mathrm{dec}}\left(t_{1 / 2}\right)$ directly. A suitable ACLM preparation can be used to calibrate both anti-factor Xa tests in terms of SIU-Xa and antithrombin tests in terms of SIU-IIa. In order to see wether the test under observation is indeed monospecific a BCLM standard can be used. A monospecific anti-thrombin test will not react to BCLM at all. A monospecific anti-factor Xa test will give the same result with an ACLM and a BCLM standard.

Monospecific anti-factor Xa tests can then be used to determine HAM (in $\mu \mathrm{g} / \mathrm{ml}$ of plasma) and monospecific anti-thrombin tests can be used to determine ACLM (idem).

\section{Practical Consequences for the Clinical Laboratory: The Over-All Tests}

Reduction of thrombosis or induction of a bleeding tendency is an over-all effect to which no doubt both ACLM and BCLM contribute, but to a different extent. Also tests like the APTT in its many varieties, tests with diluted thromboplastin, the whole blood clotting time and others, are influenced by both ACLM and BCLM (see also Table 1). It seems logical to assess the heparin effect in a patient by an overall test such as the APTT. Underlying the use of the APTT is the idea that it would be sensitive to ACLM and to BCLM in the same way as thrombosis and bleeding are. This, however, is an unproven assumption. In fact there are substances such as pentasaccharide or dermatan sulfate that hardly influence the APTT in doses that have a significant antithrombotic effect $(21,22)$. This is again seen in Table 1 , from which it also can be deduced that there is a poor correlation between the prolongation of the APTT and the inhibition of thrombin-generation by various kinds of heparin. Also the prolongation of the APTT at a fixed dose of heparin is dependent upon the individual plasma in which the heparin is dissolved (23).

A fixed prolongation of the APTT can be obtained by $a \mathrm{ng} / \mathrm{ml}$ of ACLM or by $b \mathrm{ng} / \mathrm{ml}$ of BCLM or by an infinite number of mixtures of both substances ( $1 / 2 a$ of ACLM plus $1 / 2 b$ of BCLM etc.). A given antithrombotic effect may again be obtained by $a$ $\mathrm{ng} / \mathrm{ml}$ of heparin in the patients plasma, but than is not necessarily also obtained $b \mathrm{ng} / \mathrm{ml}$ of BCLM, but e. $\mathrm{g}$. by $c \mathrm{ng} / \mathrm{ml}$ of BCLM. There is again an infinite number of mixtures that will have the same antithrombotic effect, but this series will not necessarily give an identical prolongation of the APTT. This shows that the APTT can be used without problems if we deal with ACLM only (i.e. in UFH) but looses tether as soon as mixtures with BCLM appear, i. e. in LMW heparins. The only way to understand what is indicated by a given prolongation of the APTT is to determine $a$ and $b$ as in the example above. They will probably differ even between different types of APTT.

One can imagine an ideal test that reacts to ACLM, BCLM and all other anticoagulants in the same way as the thrombotic tendency does. For the moment we can only prove that the current over-all tests are not suitable candidates. It is our guess that the thrombin potential, i.e. the surface under the thrombin generation curve might be more suitable for this purpose (24).

\section{Practical Consequences for the Characterisation of Heparins}

The approach suggested here would make it possible to compare directly the amount of anticoagulant material contained in different preparations of unfractionated as well as low molecular weight heparin. For this it is required to know: a) the content of high affinity material (HAM as \% of total); and b) the distribution of the high affinity material around the 5,400 dalton cutoff (ACLM and BCLM as \% of HAM). We need also to know: c) the specific anti-factor Xa activity of the HAM fraction and d) the specific anti-thrombin activity of the ACLM fraction. Optionally the specific anti-factor Xa activity of the ACLM and the BCLM fractions may be given. Again optionally the number average molecular weight of the HAM and the ACLM fractions, or preferably the MW distribution, might complete the characterisation.

With these data (i. e. the heparin dependent constants sub a, b, $c$ and d), it is possible to express the results of well calibrated common anti-thrombin and anti-factor Xa activity tests in terms of circulating concentrations of active (ACLM and BCLM) heparin.

The biochemical characterisation of the heparin is also a necessary prerequisite for describing its pharmacological proper- 
ties, were it only because the elimination from the circulation is significantly different for ACLM and BCLM (16).

Of course we cannot exclude the possibility that non-anticoagulant actions of heparin, notably of its LAM fraction, contribute to its antithrombotic effects, either by influencing these effects or by actions that are not related to coagulation. Such actions cannot be rigorously proven to exist unless exact quantitation of the anticoagulant effects is possible.

\section{Acknowledgements}

The authors want to thank Khaled Maroofi for expert technical help and Drs. U. Abildgaard, M. Aiach, T. W. Barrowcliffe, B. Boneu, B. Casu, C. Heuck, J.-C. Lormeau (whom we also thank for a gift of fraxiparin and its subfractions), F. Ofosu, G. Potron, M. Samama and A. Uzan for in depth discussions and helpful suggestions.

\section{REFERENCES}

1. Howell WH. The purification of heparin and its presence in blood. Am J Physiol 1925; 71: 553-62.

2. Duclos JP. L'héparine, fabrication, structure, propriétés, analyse. Masson, edts., Paris 1984; pp 233-308.

3. Van Dedem G, Van Houdenhoven F, Hennink W. The USP heparin assay, fact and artifact. In: Chemistry and Biology of Heparin, Lundblad RJ et al. (eds). New York, Amsterdam, Oxford: Elsevier/ North Holland 1981; pp 19-28.

4. Barrowcliffe TW, Curtis AD, Johnson EA, Thomas DP. An international standard for low molecular weight heparin. Thromb Haemostas 1988; 60: 1-8.

5. Coyne E, Outschoorn AS. Some thoughts on a new USP heparin assay - Aren't we ready for an upgrade? Pharmacopeial Forum 1991; 17: $1492-4$.

6. Coyne E, Outschoorn AS. Stimuli to the revision process: A clarification of quality attribute tests for heparin and heparin products. Pharmacopeial Forum 1991; 17: 1495-7.

7. Abilgaard U. Highly purified antithrombin III with heparin cofactor activity prepared by disc electrophoresis. Scand J Clin Lab Invest 1968; 21: 89-91.

8. Yin ET, Wessler S, Stoll PJ. Biological properties of the naturally occuring inhibitor to activated factor X. J Biol Chem 1971; 246: $3701-11$.

9. Rosenberg RD, Damus PS. The purification and mechanism of action of human antithrombin-heparin cofactor. J Biol Chem 1973; 248: $6490-505$.
10. Rosenberg RD. Actions and interactions of antithrombin and heparin. N Engl J Med 1975; 292: 146-51.

11. Casu B. Structure and biological activity of heparin. Adv Carb Chem Biochem 1985; 43: 51-134.

12. Barrowcliffe TW, Johnson'EA, Thomas DP. Low molecular weight heparin. Chichester: John Wiley \& Sons 1992.

13. Béguin $S$, Wielders $S$, Hemker HC. The mode of action of CY216 and CY222 in plasma. Thromb Haemostas 1992; 67: 33-41.

14. Bendetowicz AV, Pacaud E, Béguin S, Uzan A, Hemker HC. On the relationship between molecular mass and anticoagulant activity in a low molecular weight heparin (enoxaparin). Thromb Haemostas 1992; 67: 556-62.

15. Olson ST, Shore JD. Transient kinetics of heparin-catalysed proteasc inactivation by antithrombin III. The reaction step limiting heparin turnover in thrombin neutralization. J Biol Chem 1986; 261: 13151-9.

16. Hemker HC, Béguin S, Bendetowicz AV, Wielders S. The determination of the levels of unfractionated and low molecular weight heparins in plasma. Their effect on thrombin mediated feedback reactions in vivo. Preliminary results on samples after subcutaneous injection. Haemostasis 1991; 21: 258-72.

17. Béguin S, Dol F, Hemker HC. The consumption of antithrombin III and heparin during coagulation, its consequences for the calculation of prothrombinase activity and the standardisation of heparin activity. Thromb Haemostas 1992; 68: 136-42.

18. Béguin S, Lindhout T, Hemker HC. The mode of action of heparin in plasma. Thromb Hacmostas 1988; 60: 457-62.

19. Hemker HC, Béguin S. Letter to the editor. Thromb Haemostas 1993; 70: 717-8.

20. Sandset PM, Abildgaard U. Extrinsic Pathway Inhibitor - The key to feedback control of blood coagulation initiated by tissue thromboplastin. Haemostasis 1991; 21: 219-31.

21. Walenga J, Petitou M, Lormeau JC, Samama M, Fareed J, Choay J. Antithrombotic activity of a synthetic heparin pentasaccharide in a rabbit stasis thrombosis model using different thrombogenic challenges. Thromb Res 1987; 46: 187-98.

22. Ofosu FA, Buchanan MR, Anvari N, Smith LM, Blajchman MA. Plasma anticoagulant mechanisms of heparin, heparan sulfate and dermatan sulfate. In: Heparin and Related Polysaccharides. Structures and Activities. Ann New York Acad Sci 1989; 556: 123-31.

23. Van Putten JJ, van de Ruit M, Beunis M, Hemker HC. Intcrindividual variations in the relationship between plasma heparin concentrations and the results of five heparin assays. Clin Chim Acta 1982; 122: 260-71.

24. Hemker HC, Wielders S, Kessels H, Béguin S. Continuous registration of thrombin generation in plasma, its use for the determination of the thrombin potential. Thromb Haemostas 1993; in press.

Rcceived December 22, 1992 Accepted after revision June 4, 1993 